\section{Е.М. Самохина}

Evgeniya Samokhina

\section{ОЦЕНКА ДОЛГОВЫХ ЦЕННЫХ БУМАГ ДЛЯ ЦЕЛЕЙ БУХГАЛТЕРСКОЙ ОТЧЕТНОСТИ В РОССИЙСКОМ БАНКЕ}

Аннотация. В статье исследуется механизм учета иенных бумаг в кредитных организациях с учетом рекомендаций Центрального банка России, а также с учетом специфики российского рынка долговых финансовых инструментов. Автор выдвигает собственный механизм определения активного рынка. Опираясь на практический опьт и открытую информацию, автор выбирает наиболее важные аспекты цены, которые могут выступать в качестве справедливой стоимости инструментов на любом уровне. Изучение нормативно-правовой базы учета иенных бумаг и практики позволяет автору развить известную методологию учета изенных бумаг в банках.

Ключевые слова: долговые ченные бумаги, справедливая стоимость, кредитные организация, анализ рынка, бухгалтерский учет, котировки облигациий.

\title{
VALUATION OF DEBT SECURITIES FOR THE OBJECTIVES OF ACCOUNTING REPORTING IN THE RUSSIAN BANK
}

\begin{abstract}
Annotation. The article analyzes the model of market risk management with the help of a system of interrelated limits on debt securities, which take into account the risk of standards and statistical data of risk. The work proves the urgency of the problem of market risk management in credit institutions. The author, using the analysis of market risk factors, builds the structure of the securities portfolio of a credit institution for effective management. The conducted research allows the author to conduct an inseparable connection between all banking standards and a portfolio of securities.

Keywords: debt securities, fair value, credit organization, market analysis, accounting, bond quotes.
\end{abstract}

Вложения в ценные бумаги представляют собой инвестиции в ценные бумаги тех компаний, применительно к которым банк не обладает каким-либо контролем и не может оказывать значительного влияния на их деятельность. В зависимости от цели приобретения и условий реализации ценные бумаги, согласно международным стандартам финансовой отчетности (далее - МСФО), классифицируются в следующем порядке: торговые ценные бумаги; инвестиционные ценные бумаги, удерживаемые до погашения; инвестиционные ценные бумаги, имеющиеся в наличии для продажи [4].

При первоначальной идентификации, для целей российским стандартам бухгалтерской отчетности (далее - РСБУ), банк классифицирует в зависимости от цели приобретения долговые ценные бумаги в следующие категории: оцениваемые по текущей (справедливой) стоимости через прибыль или убыток; имеющиеся в наличии для продажи; удерживаемые до погашения; не погашенные в срок [2].

В соответствии с данной классификацией банк относит на определенные счета бухгалтерского учета купленные ценные бумаги: на 501 - ценные бумаги, «оцениваемые по справедливой стоимости через прибыль или убыток», 502 - «имеющиеся в наличии для продажи», 503 - «удерживаемые до погашения», 505 - «не погашенные в срок» [2].

Ценные бумаги, которые классифицируют как «оцениваемые по справедливой стоимости через прибыль или убыток», должны соответствовать следующим целям:

- получение прибыли за счет краткосрочных колебаний цены;

- продажа в краткосрочной перспективе.

(c) Самохина Е.M. 
Требования к сроку для продажи банк должен прописать в своей учетной политике, но обычно краткосрочная продажа подразумевает под собой не более 6 месяцев. При отнесении ценных бумаг в данную категорию перенос на другие счета бухгалтерского учета возможен только в случае, если эмитент не погасил долговых обязательств в установленный срок. Фактически данные ценные бумаги, согласно международному стандарту отчетности, относятся к торговым ценным бумагам [1].

Оцениваются данные ценные бумаги согласно рыночным котировкам, и их стоимость должна быть надежно определена. Результаты переоценки данных ценных бумаг отражаются в отчете о прибыли и убытках. Надежное определение стоимости ценных бумаг определяется ответственными сотрудниками банка согласно действующим регламентам определения справедливой стоимости инструмента. Резервы на возможные потери по данным ценным бумагам не формируются, и данные ценные бумаги учитываются в расчете рыночного риска банка [3].

Ценные бумаги, «имеющиеся в наличии для продажи», представляют собой вложения в ценные бумаги, которые банк предполагает удерживать в течение неопределенного периода времени. Такие ценные бумаги приобретаются с целью получения дохода, а также могут быть использованы как обеспечение по кредитам, привлекаемым банком от Центрального банка Российской Федерации и других кредитных организаций для целей управления ликвидностью банка. Данные ценные бумаги, согласно методологии международного стандарта отчетности, являются инвестиционными ценными бумагами, имеющиеся в наличии для продажи [5]. Данные ценные бумаги могут быть оцениваются либо по справедливой стоимости, либо по первоначальному признанию с формированием резерва.

Ценные бумаги, «удерживаемые до погашения», представляют собой вложения в долговые ценные бумаги, которые банк имеет намерение удерживать до погашения, вне зависимости от срока между датой приобретения и датой погашения. Долговые обязательства, «удерживаемые до погашения», и долговые обязательства, «не погашенные в срок», не переоцениваются. Под вложения в указанные ценные бумаги банк формирует резервы на возможные потери [3].

При анализе портфеля ценных бумаг российских банков на период 2013-2017 гг., можно заметить явное превосходство доли ценных бумаг «имеющихся в наличии для продажи», доля которых колеблется от $50 \%$ до $60 \%$; «оцениваемые по справедливой стоимости через прибыль или убыток» занимают долю в общих вложениях от $10 \%$ до 30 \% в зависимости от периода; доля «удерживаемые до погашения» с момента нового витка кризиса в 2015 г. возрастает с 14 \% до $35 \%$. Это обусловлено снижением суверенного рейтинга России, который упал в начале 2015 г. до неинвестиционного, что вызвало применение повышенных коэффициентов риска в оценке ценных бумаг, учитываемых в рыночном риске, поэтому часть ценных бумаг «оцениваемые по справедливой стоимости через прибыль или убыток» перешли в категорию «удерживаемые до погашения». Доля ценных бумаг, «не погашенных в срок», не превышает 1 \%. Стоит отметить суммарный рост вложений банков в ценные бумаги, который с 2013 г. вырос на 67 \% [12].

Справедливая стоимость - сумма денежных средств, необходимая и достаточная для приобретения актива или исполнения обязательства при совершении сделки между независимыми друг от друга и осведомленными участниками рынка [7].

Таким образом, МСФО определяет два рынка, где банк может использовать цены на данный актив: основной рынок, который является рынком или торговой площадкой, на котором совершаются большие обороты, который характеризуется высокой активностью рынка; наиболее выгодный рынок, который возможно использовать только при отсутствии основного и который характеризуется максимальной стоимостью, по которой можно продать актив [8]. Но стоит заметить, что у банка должен быть выход на эти два рынка, и в случае отсутствия основного или наиболее выгодного рынка, то банк может использовать информацию на рынке, на котором совершает обычно сделки по покупке или продаже ценных бумаг. 
После нахождения рынка ценной бумаги, с которого необходимо брать информацию, банк должен оценить надежность цены, которая будет использоваться при оценке ценных бумаг. Для оценки справедливой стоимости финансовых инструментов банк должен использоваться метод иерархии справедливой стоимости.

После нахождения рынка ценной бумаги, с которого необходимо брать информацию, банк должен оценить надежность цены, которая будет использоваться при оценке ценных бумаг. Для оценки справедливой стоимости финансовых инструментов банк должен использовать метод иерархии справедливой стоимости, в котором 3 уровня исходных данных для определения справедливой стоимости.

Итак, для того чтобы справедливая стоимость по ценной бумаге классифицировалась в 1-ый уровень, необходима оценка основного (либо наиболее выгодного) рынка по критериям активности.

Неактивный рынок представляет собой рынок, для которого характерны следующие особенности: совершение операций на нерегулярной основе, т.е. существенное по сравнению с периодом, когда рынок признавался активным, снижение объемов и уровня активности по операциям с ценными бумагами, существенное изменение цен за короткий период времени, а также отсутствие информации о текущих ценах [8].

Банк должен устанавливать критерии существенности для признания биржевого рынка неактивным на основании анализа биржевого рынка, используя следующие критерии.

1. Частота совершения сделок - то есть наличие менее определенного количества совершенных сделок в анализируемый период. С целью исключения формального признания рынка неактивным необходимо учитывать еще и количество дней, в которых совершались эти сделки за анализируемый период. Но последний критерий не всегда является обязательным, но он имеет значимый экономический смысл, чтобы не было манипуляций рынком, и чтобы рынок не был признан активным за сделки, совершенные в один день.

2. Оборот по совершенным сделкам - наличие оборота менее определенного значения в анализируемый период. В данном случае банк выбирает, будет ли оборот соотнесен с объемом вложений в ценную бумагу, либо будет установлен одинаковый для всех ценных бумаг вне зависимости от их выпуска и вне зависимости от вложений.

3. Котировка - если нет котировки в наблюдаемом периоде, то есть нечего использовать в качестве оценки, то рынок будет не активным, но этот критерий формальный, потому что при выполнении первых двух, с учетом того что анализируемый период для всех критериев одинаковый, этот критерий так же будет выполняться, так как при совершении хотя бы одной сделки торговая площадка рассчитывает средневзвешенную цену.

4. Наличие существенного изменения справедливой стоимости, по отношению к предыдущему значению. Также этот критерий можно использовать как разница между ценами спроса и предложения, но использование спреда не всегда является адекватным показателем, так как в данном случае может происходить манипуляция ценами, и банки обычно используют именно критерий изменения цены по сравнению с предыдущим значением.

Если основным рынком для ценной бумаге признается внебиржевой, то у банка нет возможности оценки ряда критериев по причине нераскрытия организатором торгов показателей, поэтому банк может установить критерии которыми обладают провайдеры котировок внебиржевого рынка.

После определения рынка активным банк использует котировку, предоставляемую основным рынком. Котировка активного рынка представляет собой наиболее надежное свидетельство справедливой стоимости и используется для оценки справедливая стоимость без корректировки.

В случае, когда по ценной бумаге основным рынком является биржевой рынок, то справедливой стоимостью может признаваться: 
- последняя цена предложения на покупку, то есть цена BID на день проведения переоценки, раскрываемая организатором торгов; в случае отсутствия котировки BID на день проведения переоценки, справедливой стоимостью признается цена BID на день, ближайший ко дню проведения переоценки;

- средневзвешенная цена (WAP) на дату оценки, или ближайшую средневзвешенную цену ко дню проведения переоценки (в течение 30 торговых дней).

Банк может использовать ту или иную котировку в зависимости от ее наличия, либо если BID существенно отличается от WAP, или от предыдущего значения, можно использовать WAP, чтобы не выбился один из критериев активного рынка.

В случае, когда по ценной бумаге основным рынком является внебиржевой рынок, то для целей определения справедливой стоимости, может использоваться:

- котировка BID, раскрываемая мировой информационно-аналитической системой Bloomberg (Bloomberg Generic - BGN, либо BVAL) на дату оценки, либо при отсутствии - ближайшая ко дню проведения переоценки;

- котировка Last price, раскрываемая мировой информационно-аналитической системой Bloomberg (Bloomberg Generic - BGN, либо BVAL) на дату оценки, либо при отсутствии - ближайшая ко дню проведения переоценки;

- котировка WAP, раскрываемая мировой информационно-аналитической системой Bloomberg (Bloomberg Generic - TRACE) на дату оценки, либо при отсутствии - ближайшая ко дню проведения переоценки;

- прочие котировки, предоставляемые основным рынком по данной ценой бумаге [10].

Отличие котировок BGN, BVAL и TRACE - в расчете и в используемых данных по сделкам, то есть на какой площадке проводятся операции; также существует отличие по предоставляемым данным. Так, в BGN кроме котировок ничего больше не предоставляется, в BVAL предоставляется оценка ликвидности, а также BVAL Score, который показывает значимость той или иной котировки, а в TRACE, в свою очередь, предоставляется оценка по ряду ценных бумаг, которые торгуются на площадке FINRA, но таких бумаг мало, и объемы по ним сложно оценивать. Ввиду последнего, для использования в качестве справедливой стоимости предпочтительнее BVAL, но можно использовать и BGN, так при анализе котировок трех ценных бумаг ОАО «Роснефть» и эмитента ООО «ЕвразХолдинг» (данные ценные бумаги были выбраны, потому что по ним в кризисный 2014 г. была обнаружена высокая волатильность). Средняя разница между BGN и BVAL - 0,11 процентных пункта (далее - п.п.) за 2 года по бумагам OAO «Роснефть, а по ценной бумаге ООО «ЕвразХолдинг» - 0,18 п.п., максимальная разница Роснефть 1 п.п., Евраз - 2 п.п., стоит также отметить, что BVAL был в среднем выше, чем BGN [10].

Стоит отметить, что в случае приобретения ценной бумаги на первичном размещении надежной оценкой справедливой стоимости до появления текущих котировок признается цена размещения [9].

Для установки критериев активного рынка, банк пользуется либо ретроспективным анализом портфеля вложения в ценные бумаги, и выявление верхней границы диапазона, либо экспертным методом, либо можно проанализировать весь рынок и в зависимости от величины вложений определить, когда рынок стоит признавать неактивным [6]. Банки в свою очередь стремятся снизить критерии, а центральный банк стремится наоборот сделать критерии более жесткими и отражающими текущие состояние рынка. Для отражения текущего состояния рынка Банку необходимо пересматривать свои критерии хотя бы один раз в год, либо при значимых событиях.

При проведении анализа биржевого рынка ценных бумаг в данной работе банкам рекомендуется установить следующие критерии активного рынка: 
- первым критерием выступает оборот операций за 30 торговых дней, в данном случае рекомендуется применить при консервативном подходе оборот в объеме 15 млн руб., при лояльном подходе - в объеме 10 млн руб.;

- второй критерий по количеству дней, где проходили торги за последние 30 торговых дней рекомендуется использовать критерий от 3-х;

- третий критерий по сумме сделок за 30 торговых дней рекомендуется применить при консервативном подходе - 30 сделок, при лояльном - 10 сделок;

- четвертый критерий - по существенному изменению справедливой стоимости установить в размере 15 п.п. [11].

При невозможности определения справедливой стоимости по уровню 1 справедливая стоимость определяется на основе методов оценки с использованием наблюдаемых параметров, выявляемых напрямую (т.е. в виде котировок) или косвенно (т.е. в виде параметра, производного от цены).

Для оценки справедливой стоимости (далее - СС) на уровне 2 может использоваться один из следующих подходов:

- справедливая стоимость, рассчитанная по методике ценовых центров, получивших сертификацию Центрального банка РФ [4];

- на основе иных внебиржевых котировок брокеров и маркет-мейкеров, опубликованных в Bloomberg, в том числе композитных, а также их усредненных значений. Минимальное количество используемых источников котировок брокеров и маркет-мейкеров должно быть не менее двух;

- справедливая стоимость по рассматриваемой ценной бумаге может быть определена по аналогичной или идентичной ценной бумаге при условии, что присутствует активный рынок по данной ценной бумаге.

- также исходными данными для оценки СС уровня 2 могут служить следующие наблюдаемые параметры по рынку:

- котируемые цены на идентичные или аналогичные активы на рынках, которые не являются активными;

- подразумеваемая волатильность;

- кредитные спрэды;

- подтверждаемые рынком исходные данные (например, купон, номинал);

- прочие наблюдаемые параметры [1].

Если какой-либо наблюдаемый исходный параметр требует корректировки с использованием ненаблюдаемого исходного параметра, и такая корректировка приводит к значительно более высокой или низкой оценке справедливой стоимости, то полученная в результате оценка будет отнесена к уровню 3 в иерархии справедливой стоимости.

Инструменты уровня 3 - это финансовые инструменты, которые не могут быть отнесены к инструментам уровня 1 и 2. Соответственно, их справедливая стоимость может быть определена с использованием, по крайней мере, одного ненаблюдаемого параметра, являющегося значимым для определения справедливой стоимости, или с использованием такого метода оценки, который предполагает, что совокупный эффект ненаблюдаемых параметров является значимым для оценки справедливой стоимости [1].

В рассмотренной статье описывается процесс учета ценных бумаг при покупке и дальнейшее ведение корректного учета с точки зрения долгового рынка ценных бумаг. Процесс оценки ценных бумаг и классификации для целей бухгалтерского учета достаточно трудоемкий, он требует понимания всего рынка ценных бумаг. Для того чтобы ценные бумаги отражались по справедливой стоимости, необходимо наличие правильных инструментов оценки, необходим постоянный мониторинг рынка 
и оценка влияния тенденций на текущие вложения банка. Центральный банк ужесточает политику оценки ценных бумаг для снижения манипуляций банками своего портфеля, для того чтобы в данном разрезе прибыль или убыток (далее - P\&L) банка отражали действительную переоценку всех финансовых инструментов. Все методики и параметры оценки ценных бумаг проверяются на регулярной основе, как и аудиторами банка, так и Центральным банком. И у всех банков стоит задача найти компромисс между требованиями регулятора и собственными P\&L, собственными ресурсами оценки. Так же цель Центрального банка снизить долю неликвидных ценных бумаг в портфеле банка, так как данные ценные бумаги являются высокорискованными вложениями и могут в моменты кризиса существенно повлиять на результаты деятельности банковского сектора в целом.

\section{Библиографический список}

1. Международный стандарт финансовой отчетности (IFRS) 13 «Оценка справедливой стоимости»: введен в действие на территории Российской Федерации Приказом Минфина России от 28.12.2015 № 217н [Электронный pecypc]. - Режим доступа: Справочная правовая система «КонсультантПлюс» (дата обращения: 25.11.2017).

2. Положение о Плане счетов бухгалтерского учета для кредитных организаций и порядке его применения: утв. Банком России 27.02.2017 N 579-П - ред. от 05.07.2017 - Зарегистрировано в Минюсте России 20.03.2017 № 46021 [Электронный ресурс]. - Режим доступа: Справочная правовая система «КонсультантПлюс» (дата обращения: 25.11.2017).

3. Положение о порядке формирования кредитными организациями резервов на возможные потери: утв. Банком России 20.03.2006 № 283-П - ред. от 04.08.2016. Зарегистрировано в Минюсте России 25.04.2006 - № 7741 [Электронный ресурс]. - Режим доступа: Справочная правовая система «КонсультантПлюс» (дата обращения: 25.11.2017).

4. Письмо Банка России от 29.12.2009 № 186-Т «О Методических рекомендациях об оценке финансовых инструментов по текущей (справедливой) стоимости» [Электронный ресурс]. - Режим доступа: Справочная правовая система «КонсультантПлюс» (дата обращения: 25.11.2017).

5. Богданова, Н. В. Методика отражения ценных бумаг по МСФО / Н. В. Богданова // МСФО и МСА в кредитной организации. - 2005. - № 6 [Электронный ресурс]. - Режим доступа: http:/gaap.ru/articles/metodika_otrazheniya tsennykh_bumag_po_msfo_ias_32_ias_39/(дата обращения: 30.11.2017).

6. Бочаров, В. В. Инвестиции / В. В. Бочаров. - СПб. : Питер, 2006. -455 с.

7. Грязнова, А. Г. Финансово-кредитный энциклопедический словарь / А. Г. Грязнова А.Г. - М. : Финансы и статистика, 2005. $-1168 \mathrm{c.}$

8. Жуков, Е. В. Рынок ценных бумаг / Е. В. Жуков, О. И. Дягтярева, Н. М. Коршунов. - М. : ЮНИТИ, 2009.- 567 с.

9. Ильина, Л. И. Организация и финансирование инвестиций: Учебное пособие / Л. И. Ильина. -Сыктывкар, 2002. $-400 \mathrm{c}$.

10. Информационный портал Bloomberg [Электронный ресурс]. - Режим доступа: https://www.bloomberg.com/ (дата обращения: 27.11.2017).

11. Сайт Московской биржи [Электронный ресурс]. - Режим доступа: http://www.moex.com/ (дата обращения: 25.11.2017).

12. Сайт Центрального банка [Электронный ресурс]. - Режим доступа: https://www.cbr.ru/ (дата обращения: 25.11.2017).

\section{References}

1. International Financial Reporting Standard 13 «Estimation of fair value»: entered into force on the territory of the Russian Federation by the Order of the Ministry of Finance of Russia from December 28, 2015 № 217H. Available at: Spravochnaja pravovaja sistema «Konsul'tantPljus» [ConsultantPlus legal reference system] (Accessed: 25 November 2017).

2. Regulations on the Chart of Accounts for Credit Organizations and the Order of Its Application [Electronic resource]: Bank of Russia 27.02.2017 № 579-П. Ed. on 05.07.2017. Registered with the Ministry of Justice of Russia on 03.20.2017 - № 46021. Available at: Spravochnaja pravovaja sistema «Konsul'tantPljus» [ConsultantPlus legal reference system] (Accessed: 25 November 2017). 
3. Regulation on the procedure for the formation of reserves by credit institutions for possible losses: approved. Bank of Russia dated 20.03.2006 № 283-П. Ed. on 04.08.2016. Registered with the Ministry of Justice of Russia on 25.04.2006 - № 7741. Available at: Spravochnaja pravovaja sistema «Konsul'tantPljus» [ConsultantPlus legal reference system] (Accessed: 25 November 2017).

4. Letter of the Bank of Russia dated 29.12.2009 № 186-T «On Methodological Recommendations on the valuation of financial instruments at current (fair) value». Available at: Spravochnaja pravovaja sistema «Konsul'tantPljus» [ConsultantPlus legal reference system] (Accessed: 25 November 2017).

5. Bogdanova N.V. Metodika otrazheniya cennyh bumag po MSFO [Methodology for the reflection of securities under IFRS]. MSFO i MSA v kreditnoj organizacii [IFRS and ISA in a credit institution], 2005, I. 6. Available at: http://gaap.ru/articles/metodika_otrazheniya_tsennykh_bumag_po_msfo_ias_32_ias_39/ (Accessed: 30 November 2017).

6. Bocharov V. V. Investicii [Investments]. Saint Petersburg, Piter, 2006. 455 p.

7. Gryaznova A. G. Finansovo-kreditnyj enciklopedicheskom slovar' [Financial and credit encyclopedic dictionary]. Moscow, Finansy i statistika, 2005. 1168 p.

8. Zhukov E.V., Dyagtyareva O.I., Korshunov N.M. Rynok cennyh bumag [Stocks and bods market]. Moscow, YUNITI, 2009. $567 \mathrm{p}$.

9. Ilyina L. I. Organizaciya i finansirovanie investicij: Uchebnoe posobie [Organization and financing of investments]. Syktyvkar, 2002. 400 p.

10.Information portal Bloomberg. Available at: https://www.bloomberg.com/ (Accessed: 27 November 2017).

11.The site of the Moscow Stock Exchange. Available at: http://www.moex.com/ (Accessed: 25 November 2017).

12. Central Bank website. Available at: https://www.cbr.ru/ (Accessed: 25 November 2017). 